\title{
Uji Aktivitas Antiradikal Bebas Ekstrak Daun Paliasa (Kleinhovia hospita Linn.)
}

Silviana Hasanuddin'1, Citra Andini²

1STIKES Mandala Waluya Kendari

${ }^{2}$ Akademi Farmasi Bina Husada Kendari

\begin{abstract}
ABSTRAK
Telah dilakukan identifikasi senyawa antiradical bebas pada ekstrak daun paliasa (K. hospita).Penelitian ini bertujuan untuk mengidentifikasi senyawa antiradical bebas berdasarkan aktivitas pengikat radikal bebas DPPH (1,1-Diphenyl-2-picryl Hydrasil) ekstrak daun paliasa.

Daun paliasa diekstraksi dengan cara maserasi menggunakan pelaru n-heksan kemudian ampas dari maserasi dengan n-heksan dimaserasi lagi dengan etanol 96\%. Ekstrak etanol kemudian dipartisi dengan pelarut etil asetat. Ekstrak nheksan, etanol dan fraksi etil asetat memiliki aktivitas radikal bebas dengan nilai IC50 berturutturut adalah untuk ekstrak N-heksan sebesar 28,713

menunjukkan perubahan warna dari ungu menjadi kuning. Sedangkan pada penyemprotan dengan menggunakan reagen antimmon (III) klorida memperlihatkan bercak berpendar kuning pada UV 366 yang menandakan bahwa daun paliasa mengandung golongan senyawa flavanoid.

Identifikasi KLT-Bioautografi menunjukkan bahwa ekstrak daun paliasa aktif sebagai antiradical bebas dimana bercak menunjukkan perubahan warna dari ungu menjadi kuning. Sedangkan pada penyemprotan dengan menggunakan reagen antimmon (III) klorida memperlihatkan bercak berpendar kuning pada UV 366 yang menandakan bahwa daun paliasa mengandung golongan senyawa flavanoid
\end{abstract} $\mathrm{mg} / \mathrm{ml}$, nilai IC 50 untuk ekstrak etano Sebesar $3,113 \mathrm{mg} / \mathrm{ml}$ dan nilai IC 50 untuk fraksi etil asetat sebesar $4,556 \mathrm{mg} / \mathrm{ml}$. Sedang nilai IC 50 dari sampel pembanding yaitu vitamin C 0,106 mg/ml dan BHT 0,067 mg/ml. Identifikasi KLT-autografi menunjukkan bahwa ekstrak daun paliasa aktif sebagai antiradical bebas dimana bercak
Kata kunci : Antiradikal bebas, Daun Paliasa.

Penulis korespondensi :

Silviana Hasanuddin

STIKES Mandala Waluya Kendari

silviana.hasanuddin@gmail.com

\section{PENDAHULUAN}

Antioksidan merupakan sebutan untuk zat yang berfungsi melindungi tubuh dari serangan radikal bebas, yang termasuk dalam golongan zat ini antara lain vitamin, polifenol, karotin, dan mineral. Secara alami, antioksidan ini sangat besar peranannya pada manusia untuk mencegah terjadinya penyakit. Antioksidan melaukan semua itu dengan cara menekankan kerusakan sel yang terjadi akibat proses oksidasi radikal bebas (Anonim, 2008).

Antioksidan dapat diperoleh dari tumbuh-tumbuhan, sayur-sayuran dan 
buah-buahan. Salah satu tumbuhan tersebut adalah daun paliasa. Daun peliasa merupakan salah satu tanaman obat yang dikenal masyarakat Sulawesi Selatan yang berfungsi untuk mengobati penyakit kuning (Suryawati, 1991), menurunkan kolesterol, hipertensi serta diabetes (Herlina, 1993) dan kanker hati (Tayeb, 2009).

Paliasa termasuk dalam family Sterculiaceae mengandung senyawa kimia seperti sianogenik, alkaloid, proantosianin, sianidin, flavanol, kaemferol dan quercetin serta saponin (Watson, 1992).

Bebrapa hasil penelitian sebelumnya membuktikan bahwa daun paliasa (K. hospital Linn). Fraksi n-heksan aktif terhadap udang Artemia salina Leach (Hendra, 2005), dekok daun paliasa (K.

\section{METODOLOGI PENELITIAN}

A. Jenis penelitian

Jenis penelitian ini dilakukan secara eksperimental yang merupakan npenelitian laborarotium.

B. Pembuatan Ekstrak Daun Kucai

Pembuatan ekstrak daun kucai dalam penelitian ini dilakukan dengan metode maserasi, yaitu simplisia di timbang sebanyak 300 gram, dimasukkan dalam wadah maserasi dan direndam hospital Linn) sebagai obat radang hati akut terhadap tikus putih betina strain wistar (Raflizar, 2006). Uji farmakokinetika dengn menggunakan hewan percobaan dan hasilnya menunjukkan bahwa wkatrak daun paliasa dapat melindungi radang hati tikus (Raflizar, 2006), infuse daun paliasa mempunyai efek antidiabetes dengan mekanisme penghambatan terhadap transport aktif glukosa pada usus halus marmot (Hasni, 2002), sebagai obat anti tumor dalam sarcoma mencit (Latif, 1997).

Inilah yang mendasari peneliti untuk melakukan penelitian pengujian tentang uji daya hambar antioksidan dari ekstrak etanol, ekstrak n-heksan dari fraksi etil asetat dari daun paliasa (K.Hospita Linn) dengan menggunakan DPPH.

dengan larutan $n$-heksan sampai terendam lalu diaduk hingga homogen, tutup segera kemudian disimpan dalam ruangan yang terhindar dari cahaya matahari selama 5 hari sambil sesekali di aduk. Setelah direndam selama 5 hari, disaring dengan menggunakan kertas saring sehingga diperoleh filtrate (ekstrak cair). Hasil penyarian n-heksan dikumpulkan, diuapkan dengan rotavapor hingga diperoleh ekstrak cair. Kemudian 
dianginanginkan. Ekstrak kental diperoleh 38 gram.

Ampas hasil ekstraksi direndam lagi dengan etanol sebanyak 3 liter hingga simplisia tersebut terendam, dibiarkan selama 3 hari dalam bejana tertutup dan terlindung dari cahaya sambil berulangulang diaduk. Kemudian simplisia disaring dan residunya direndam lagi dengan cairan penyari yang baru. Hal ini dilakukan selama 3 kali. Hasil penyari yang didapat dikumpulkan dan diuapkan dengan rotavapor ekstrak etanol yang kental. Didapatkan ekstrak kental sebanyak 12 gram.

B. Partisi Sampel dengan Pelarut Etil Asetat

Ekstrak etanol yang diperoleh diambil sebanyak 12 gram, untuk diekstraksi dengan pelarut etil asetat dengan cara partisi cair-cair. Ekstrak etanol sebenyak 5 gram disuspensikan dengan air sebanyak $50 \mathrm{ml}$, kemudian dimasukan kedalam corong pisah untuk dipartisi dengan n-heksan sebanyak $50 \mathrm{ml}$, kemudian dikocok. Sesekali penutup corong dibuka setelah itu didiamkan selama 30 menit sampai terjadi pemisahan antara lapisan etil asetat (fraksi etil asetat) dan lapisan air (residu). Residu dipartisi kembali sesuai dengan cara diatas, dilakukan berulang hingga jernih. Fraksi etil asetat dikumpulkan dan diucapkan hingga diperoleh fraksi etil asetat.

C. Pembuatan larutan DPPH

Larutan DPPH 0,4 M dengan cara ditimbang DPPH sebanyak $15 \mathrm{mg}$, kemudian dilarutkan dengan $100 \mathrm{ml}$ etanol absolute dalam labu terukur.

D. Uji Aktivitas Radikal bebas

a. Ekstrak kering etanol, n-heksan dan fraksi daun paliasa ditotolkan pada lempeng KLT kemudian dielusi dengan menggunakan eluen yang sesuai. Lempeng KLT disemprot dengan menggunakan DPPH dan dibiarkan selama \pm 30 menit hingga terjadi perubahan warna dari ungu ke kuning

b. Pengukuran Blanko

Pengujian dilakukan dengan memipet 1,0 DPPH 0,4 mM dan cukupkan volumenya dengan etanol absolute sampai 5,0 ml dalam labu terukur. Larutanini kemudian dibiarkan selama 30 menit dan selanjutnya diukur absorbansinya pada panjang gelombang $517 \mathrm{~nm}$.

c. Pengukuran antiradical bebas ekstrak daun paliasa

Larutan 1\% disiapkan dengan cara menimbang daun paliasa sebanyak $50 \mathrm{mg}$ dan dilarutkan dengan etanol absolute sambil diaduk dan dihomogenkan dengan 
bentuan vortex, volume akhir dicukupkan hingga 5,0. Untuk mendapatkan konsentrasi $0,5 \%, 0,25 \%$ dan 0,1 \% dipipet masing-masing $500 \mu \mathrm{l}$, dan $100 \mu \mathrm{l}$ larutan stok dan volume dicukupkan dengan etanol absolute hingga $1 \mathrm{ml}$. pengujian dilakukan dengan memipet $100 \mu$ larutan sampel dari berbagai konsentrasi masingmasing ditambah 1,0 ml DPPH 0,4 mM dan dicukupkan volumenya sampai 5,0 ml dengan etanol absolute dalam labu terukur. Campuran selanjutnya dihomogenkan lalu dibiarkan pada suhu kamar selama 30 menit. Serapannya diukur pada panjang gelombang $517 \mathrm{~nm}$.

d. Pengukuran daya anti radikal bebas sampel pembanding

Larutan stok 0,01\% disiapkan dengan cara menimbang Vitamin $\mathrm{C}$ dan BHT masing-masing sebanyak $1 \mathrm{mg}$ dan dilarutkan dengan aquadest sambil diaduk dan dihomogenkan dengan bantuan vortex, volume akhir dicukupkan hingga $10 \mathrm{ml}$. konsentrasi larutan 0,005\%, $0,0025 \%$ dan 0,00125\% dibuat dengan mengambil masing-masing $500 \mu \mathrm{l}, 250 \mu \mathrm{l}$, dan $125 \mu \mathrm{l}$ larutan stok dan volume dicukupkan dengan aquadest hingga $1 \mathrm{ml}$. pengujian dilakukan dengan memipet 100 $\mu$ larutan dari berbagai konsenrasi masing-masing ditambah 1,0 $\mathrm{ml} \mathrm{DPPH} \mathrm{0,4}$
mM dan dicukupkan volumenya sampai 5,0 $\mathrm{ml}$ dengan etanol absolute dalam labu terukur. Campuran selanjutnya dihomogenkan lalu dibiarkan pada suhu kamar selama 30 menit serapannya diukur pada panjang gelombang $517 \mathrm{~nm}$.

\section{HASIL DAN PEMBAHASAN}

Simplisia daun paliasa (Kleinhovia hospital Linn) sebnyak 300 gram diekstraksi secara maserasi menggunakan pelarut n-heksan, menghasilkan ekstrak kental sebanyak 38 gram. Ampas hasil maserasi dengan n-heksan dimaserasi kembali dengan etanol, menghasilkan ekstrak etanol kental sebanyak 12 gram. Ekstrak etanol kemudian diambil sebanyak 5 gram dipartisi dengan etil asetat menghasilkan 2,25 gram. Ketiga ekstrak tersebut diuji aktifitas antiradical bebas secara kualitatif dan kuantitatif dengan metode DPPH dan diperoleh nilai $\mathrm{IC}_{50}$ untuk ekstrak etanol sebesar 3,113 $\mathrm{mg} / \mathrm{ml}$, nilai IC 50 untuk ekstrak n-heksan sebesar $28,713 \mathrm{mg} / \mathrm{ml}$ dan nilai $\mathrm{IC}_{50}$ untuk fraksi etil asetat sebesar 4,556 mg/ml.

Nilai IC $_{50}$ dari setiap sampel dibandingkan dengan vitamin $\mathrm{C}$ dan BHT. Pengukuran aktivitas sampel pembanding vitamin $\mathrm{C}$, diperoleh nilai $\mathrm{IC}_{50}$ sebesar 0,106 g/ml, sedangkan untuk BHT 0,067 $\mathrm{mg} / \mathrm{ml}$. hasil pengukuran serapan pada 
spektrofotometer UV-Vis $517 \quad \mathrm{~nm}$ diperoleh persentase pengikatan radikal bebas sebagai berikut:

Tabel.1 Hasil Pengukuran absorbansi, persentase Pengikatan DPPH dan Nilai $\mathrm{IC}_{50}$ dari daun paliasa (Kleinhovia hospital Linn).

\begin{tabular}{|c|c|c|c|c|}
\hline $\begin{array}{c}\text { Samp } \\
\text { el }\end{array}$ & $\begin{array}{c}\text { Konsentr } \\
\text { asi } \\
(\mathrm{mg} / \mathrm{ml})\end{array}$ & $\begin{array}{c}\text { Absorba } \\
\text { nsi }\end{array}$ & $\begin{array}{c}\text { \%pengikat } \\
\text { an } \\
\text { radikal } \\
\text { bebas } \\
\text { rata-rata }\end{array}$ & $\begin{array}{c}\mathrm{IC}_{50} \\
(\mathrm{mg} / \mathrm{m} \\
\mathrm{l})\end{array}$ \\
\hline \multirow{12}{*}{$\begin{array}{c}\text { Ekstra } \\
k \\
\text { etanol }\end{array}$} & \multirow{3}{*}{10} & 0,223 & \multirow{3}{*}{$\begin{array}{c}80,489 \\
\%\end{array}$} & \multirow{12}{*}{3,113} \\
\hline & & 0,223 & & \\
\hline & & 0,223 & & \\
\hline & \multirow{3}{*}{5} & 0,262 & \multirow{3}{*}{$77,077 \%$} & \\
\hline & & 0,262 & & \\
\hline & & 0,262 & & \\
\hline & \multirow{3}{*}{2,5} & 0,577 & \multirow{3}{*}{$49,518 \%$} & \\
\hline & & 0,577 & & \\
\hline & & 0,577 & & \\
\hline & \multirow{3}{*}{1} & 0.839 & \multirow{2}{*}{$26,596 \%$} & \\
\hline & & 0,840 & & \\
\hline & & 0,840 & & \\
\hline \multirow{12}{*}{$\begin{array}{c}\text { Ekstra } \\
\text { k } \\
\text { n- } \\
\text { heksa } \\
\text { n }\end{array}$} & \multirow{3}{*}{10} & 0,797 & \multirow{3}{*}{$30,271 \%$} & \\
\hline & & 0,797 & & \\
\hline & & 0,798 & & \\
\hline & \multirow{3}{*}{5} & 0,814 & \multirow{3}{*}{$28,696 \%$} & \\
\hline & & 0,815 & & \\
\hline & & 0,816 & & \\
\hline & \multirow[t]{3}{*}{2,5} & 0,872 & \multirow{3}{*}{$23,709 \%$} & \\
\hline & & 0,872 & & \\
\hline & & 0,872 & & \\
\hline & \multirow{3}{*}{1} & 0,902 & \multirow{3}{*}{$21,085 \%$} & \\
\hline & & 0,901 & & \\
\hline & & 0,902 & & \\
\hline \multirow{7}{*}{$\begin{array}{c}\text { Fraksi } \\
\text { etil } \\
\text { Asetat }\end{array}$} & \multirow[t]{3}{*}{10} & 0,271 & \multirow{3}{*}{$76,902 \%$} & \\
\hline & & 0,271 & & \\
\hline & & 0,521 & & \\
\hline & \multirow{3}{*}{5} & 0,521 & \multirow{3}{*}{$54,768 \%$} & \multirow{4}{*}{4,556} \\
\hline & & 0,521 & & \\
\hline & & 0,508 & & \\
\hline & 2,5 & 0,618 & $45,932 \%$ & \\
\hline
\end{tabular}

\begin{tabular}{|l|l|l|l|}
\hline \multirow{2}{*}{} & 0,617 & \multirow{4}{*}{} \\
& 0,618 & \\
\cline { 3 - 3 } & \multirow{3}{*}{1} & 0,870 & \multirow{3}{*}{$\begin{array}{c}\text { 3,884 } \\
\%\end{array}$} \\
& 0,870 & \\
& & 0,870 & \\
\hline
\end{tabular}

Tabel 2. Hasil Pengukuran Absorbansi, Persentase Pengikatan DPPH dan Nilai IC dari sampel pembanding vitamin $C$ dan BHT

\begin{tabular}{|c|c|c|c|c|}
\hline Sampel & $\begin{array}{c}\text { Konsentr } \\
\text { asi } \\
(\mathrm{mg} / \mathrm{ml})\end{array}$ & $\begin{array}{c}\text { Absorban } \\
\text { si }\end{array}$ & $\begin{array}{c}\text { \%pengikata } \\
\mathbf{n} \\
\text { radikal } \\
\text { bebas rata- } \\
\text { rata }\end{array}$ & $\begin{array}{r}\mathrm{IC}_{50} \\
(\mathrm{ppm})\end{array}$ \\
\hline & \multirow[t]{2}{*}{0,1} & \multirow{2}{*}{$\begin{array}{l}0,606 \\
0,606\end{array}$} & & \\
\hline & & & $47,069 \%$ & \\
\hline & & 0,604 & & \\
\hline & 0,05 & 0,902 & \multirow{2}{*}{$20,997 \%$} & \\
\hline & & 0,903 & & \\
\hline \multirow{10}{*}{$\begin{array}{c}\text { Vitami } \\
\text { n C }\end{array}$} & & 0,905 & & \multirow[t]{2}{*}{0,106} \\
\hline & \multirow[t]{3}{*}{0,025} & 1,023 & \multirow[t]{2}{*}{$11,199 \%$} & \\
\hline & & 1,023 & & \\
\hline & & 1,000 & & \\
\hline & \multirow[t]{3}{*}{0,0125} & 1,126 & \multirow[t]{3}{*}{$1,662 \%$} & \\
\hline & & 1,126 & & \\
\hline & & 1,120 & & \\
\hline & \multirow[t]{3}{*}{0,1} & 0,403 & \multirow[t]{3}{*}{$64,742 \%$} & \\
\hline & & 0,403 & & \\
\hline & & 0,403 & & \\
\hline \multirow[t]{8}{*}{ BHT } & \multirow[t]{3}{*}{0,05} & 0,677 & \multirow[t]{3}{*}{$40,769 \%$} & \\
\hline & & 0,677 & & \\
\hline & & 0,678 & & 0,067 \\
\hline & \multirow[t]{3}{*}{0,025} & 0,753 & \multirow[t]{3}{*}{$34,121 \%$} & \\
\hline & & 0,753 & & \\
\hline & & 0,752 & & \\
\hline & \multirow[t]{2}{*}{0,0125} & 0,902 & \multirow[t]{2}{*}{$20,997 \%$} & \\
\hline & & 0,903 & & \\
\hline
\end{tabular}


Tabel 3. Nilai Rf dan Warna Bercak pada Profil Kromatograf Lapis Tipis Ekstrak Daun Paliasa (Kleinhovia hospitaLinn.)

\begin{tabular}{|c|c|c|c|c|c|c|c|}
\hline \multirow[t]{2}{*}{ Sampel } & \multirow[t]{2}{*}{ Bercak } & \multicolumn{2}{|c|}{ UV 254} & \multicolumn{2}{|c|}{ UV 366} & \multicolumn{2}{|c|}{ DPPH } \\
\hline & & $\mathbf{R f}$ & Warna & $\mathbf{R f}$ & Warna & $\mathbf{R f}$ & Warna \\
\hline $\begin{array}{c}\text { Ekstrak } \\
\text { Etanol }\end{array}$ & $\begin{array}{l}\text { I } \\
\text { II } \\
\text { III } \\
\text { IV } \\
\text { V } \\
\text { VI } \\
\text { VII }\end{array}$ & $\begin{array}{l}0,54 \\
0,45 \\
0,34\end{array}$ & $\begin{array}{l}\text { Kuning } \\
\text { Kuning } \\
\text { Kuning }\end{array}$ & $\begin{array}{l}0,78 \\
0,67 \\
0,54 \\
0,45 \\
0,33 \\
0,25 \\
0,11\end{array}$ & $\begin{array}{l}\text { Jingga } \\
\text { Jingga } \\
\text { Jingga } \\
\text { Jingga } \\
\text { Jingga } \\
\text { Jingga } \\
\text { Ungu } \\
\text { kebiruan }\end{array}$ & 0,11 & kuning \\
\hline $\begin{array}{l}\text { Ekstrak } \\
\text { n-heksan }\end{array}$ & $\begin{array}{l}\text { I } \\
\text { II } \\
\text { III } \\
\text { IV } \\
\text { V } \\
\text { VI } \\
\text { VII } \\
\text { VIII }\end{array}$ & $\begin{array}{l}0,98 \\
0,95 \\
0,89 \\
0,76 \\
0,65 \\
0,51 \\
0,2 \\
0,16\end{array}$ & \begin{tabular}{|l} 
Kuning \\
Kuning \\
Kuning \\
Hijau \\
Hijau \\
Kuning \\
Kuning \\
kuning
\end{tabular} & $\begin{array}{l}0,98 \\
\\
0,93 \\
0,84 \\
0,76 \\
0,64 \\
0,42\end{array}$ & $\begin{array}{l}\text { Coklat } \\
\text { kekuningan } \\
\text { Ungu muda } \\
\text { Ungu muda } \\
\text { Jingga } \\
\text { Jingga } \\
\text { Coklat }\end{array}$ & $\begin{array}{l}0,98 \\
0,93 \\
0,87\end{array}$ & $\begin{array}{l}\text { Kuning } \\
\text { Kuning } \\
\text { Kuning }\end{array}$ \\
\hline $\begin{array}{l}\text { Ekstrak } \\
\text { Etil asetat }\end{array}$ & $\begin{array}{l}\text { I } \\
\text { II } \\
\text { III } \\
\text { IV } \\
\text { V } \\
\text { VI }\end{array}$ & $\begin{array}{l}0,58 \\
0,53 \\
0,44 \\
0,36 \\
0,29 \\
0,24\end{array}$ & $\begin{array}{l}\text { Hijau } \\
\text { Hijau } \\
\text { Hijau } \\
\text { Hijau } \\
\text { Hijau } \\
\text { Hijau }\end{array}$ & $\begin{array}{l}0,78 \\
0,65 \\
0,53 \\
0,44 \\
0,31 \\
0,24\end{array}$ & $\begin{array}{l}\text { Jingga } \\
\text { Jingga } \\
\text { Jingga } \\
\text { Jingga } \\
\text { Jingga } \\
\text { Jingga }\end{array}$ & 0,13 & Kuning \\
\hline
\end{tabular}

Uji daya antiradikal bebas dilakukan dengan metode Blois yang menggunakan DPPH (1,1-Diphenyl2-Picryl Hydrazil). DPPH merupakan radikal sintetik yang larut dalam pelarut polar seperti metanol dan etanol, dapat diukur intensitasnya pada panjang gelombang 517 nm. Pemilihan DPPH dipilih karena sederhana, mudah, cepat dan hanya memerlukan sedikit sampel sudah dapat memberikan aktivitas yang diinginkan. Senyawa antioksidan akan bereaksi dengan radikal bebas (DPPH) melalui mekanisme donasi atom hidrogen dan menyebabkan terjadinya perubahan warna DPPH dari ungu 
ke kuning yang diukur pada panjang gelombang $517 \mathrm{~nm}$. Aktivitas radikal bebas ditunjukkan dengan IC50. Nilai IC50 merupakan nilai konsentrasi antioksidan untuk meredam 50\% aktivitas radikal bebas. Menurut Blois menyatakan bahwa ekstrak dengan nilai IC50 yang kurang dari $200 \mu \mathrm{g} / \mathrm{ml}$ memiliki aktivitas antioksidan yang kuat. Semakin kecil nilai IC50berarti semakin kuat daya antioksidannya.

Ketiga ekstrak yang diperoleh diuji aktivitas antiradical bebas dan diperoleh nilai $\mathrm{IC}_{50}$ untuk ekstrak etanol sebesar $3,113 \mathrm{mg} / \mathrm{ml}$, nilai $\mathrm{IC}_{50}$ untuk ekstrak N-heksan sebesar 28,713 $\mathrm{mg} / \mathrm{ml}$, dan nilai IC untuk fraksi etil asetat sebesar 4,556 mg/ml.

$\begin{array}{ccr}\text { Sedang } & \text { nilai } & \text { ICdari } \\ \text { sampel } & \text { pembanding } & \text { yaitu }\end{array}$
vitamin C 0,106 mg/ml dan BHT 0,067 $\mathrm{mg} / \mathrm{ml}$. Ini menunjukkan bahwa ekstrak etanol yang memiliki aktivitas antioksidan yang paling kuat, walaupun aktivitasnya lebih rendah jika dibandingkan dengan vitamin $\mathrm{C}$ dan BHT.
Gambar profil KLT dan nilai Rf untuk setiap sampel dapat dilihat pada tabel 3. Sedangkan pada penyemprotan dengan menggunakan reagen antimmon (III) klorida memperlihatkan bercak berpendar kuning pada UV 366 yang menandakan bahwa daun paliasa mengandung golongan senyawa flavanoid. Perubahan warna ini terjadi karena adanya fungsi lingkaran teroksidasi pada senyawa flavanoid yang bereaksi sebagai ligan-ligan ketika ditambahkan dengan antimmon (III) klorida yang merupakan logam.

\section{KESIMPULAN}

Berdasarkan hasil penelitian yang dilakukan dapat disimpulkan Nilai IC untuk ekstrak etanol sebesar 3,113 $\mathrm{mg} / \mathrm{ml}$, nilai $\mathrm{IC}_{50}$ ekstrak N-heksan sebesar $28,713 \mathrm{mg} / \mathrm{ml}$, dan nilai $\mathrm{IC}_{50}$ untuk fraksi etil asetat sebesar 4,556 $\mathrm{mg} / \mathrm{ml}$. Sedang nilai IC50 dari sampel pembanding yaitu vitamin C 0,106 mg/ml dan BHT 0,067 mg/ml. Ini menunjukkan bahwa ekstrak etanol yang memiliki aktivitas antioksidan yang paling kuat, walaupun aktivitasnya lebih rendah jika dibandingkan dengan vitamin C dan BHT. 


\section{DAFTAR PUSTAKA}

Anonim, 2008, Antioksidan, Info

Kesehatan,

(Online),

(http:www.blogdokter.net/2008/

10/20/antioksidan/trackback,

diakses 19 April 2011).

Dirjen POM., 1979. Farmakope Indonesia,

Edisi III. Departemen Kesehatan

Republik Indonesia:Jakarta.

Hasni, 2002, Pengaruh Infus Daun

Paliasa (Kleinhovia hospita Linn.)

Terhadap Transport Aktif Glukosa

Pada Usus Halus Marmut, Skripsi, Jurusan Farmasi, FMIPAUNHAS: Makassar.

Hendra, E, 2005, Isolasi Dan Identifikasi Senyawa Metabolit Sekunder Fraksi n-Heksan Yang Non Aktif Terhadap Artemia salina Leach Ekstrak daun Paliasa (Kleinhovia hospita Linn.) Skripsi, Jurusan farmasi, FMIPAUNHAS: Makassar.

Latif, A., 1997, Kleinhovia hospita Linn. Faridah, H.I. Dan L.J.G Van Den Maese, "Plant Resources Of SouthEast Asia No II ", Diterbitkan Jurusan Kimia.

Raflizar, dkk., 2006, Dekok Daun Paliasa (Kleinhovia hospita Linn.) Sebagai Obat Radang Hati Akut, (Online),(http:www.kalbe.co.idfil escdkfiles06_150_DekokDaunPali
asaObatRadang.pdf06_150_Deko kDaunPaliasaObatRadang.html, Diakses April 2011).

Tayeb,R., 2009, Isolasi Senyawa Aktif Antikanker Ekstrak Metanol Daun Paliasa (Melochia umbellate (Houtt) Staff Var.deglabratan, (Online), ( http://www.unhas.ac.id/lppm/i ndex.php?option=com_content\& view $=$ article\&id=88:bidang-ilmufarmasi\&catid=35:abstrak2009\&Itemid= 63, DiaksesApril2011).

Watson, L. 1992, The Families Of Flowering Plants: Sterculiaceae Vent, (Online),

(Http:/ / www.sterculiaceae,html, diakses April 11).

Wijayakusuma, H., 1992. Tanaman Berkhasiat Obat Di Indonesia, Jilid I.Pustaka Kartini: Jakarta. 